\title{
CORRELATES OF ACHIEVING THE GUIDELINES OF FOUR FORMS OF PHYSICAL ACTIVITY, AND THE RELATIONSHIP BETWEEN GUIDELINES ACHIEVEMENT AND ACADEMIC PERFORMANCE: UNDERGRADUATE STUDENTS IN FINLAND
}

\author{
Walid El Ansari ${ }^{1,2,3,4}$, Sakari Suominen ${ }^{2,5}$, Steve Draper ${ }^{6}$ \\ 'Department of Surgery, Hamad General Hospital, Doha, Qatar \\ ${ }^{2}$ College of Medicine, Doha, Qatar \\ ${ }^{3}$ School of Health and Education, University of Skövde, Skövde, Sweden \\ ${ }^{4}$ Faculty of Applied Sciences, University of Gloucestershire, Gloucester, United Kingdom \\ ${ }^{5}$ University of Turku, Department of Public Health, Turku, Finland \\ ${ }^{6}$ University Centre Hartpury, Gloucester, United Kingdom
}

\section{SUMMARY}

Objectives: We surveyed and compared, by gender, the levels and correlates of achieving the international guidelines of four forms of physical activity (PA): moderate PA (MPA), vigorous PA (VPA), moderate or vigorous PA (MVPA), and muscle strengthening PA (MSPA). The study assessed the associations between achieving the guidelines of the four PA forms and a range of socio-demographic, health and academic performance variables.

Methods: Data was collected across the seven faculties of the University of Turku (2013-2014 from a representative sample of 1,189 undergraduates). An English language online self-administered questionnaire assessed frequency and duration of PA/week for each form of PA. We employed cut-offs for the guidelines in accordance with the American Heart Association. Chi-square statistic tested the differences in PA, socio-demographic variables and academic performance between males and females. Binary logistic regression examined the factors associated with achieving the four PA guidelines and linear regression examined the association between the frequency of PA and academic performance.

Results: Achievement of PA guidelines was relatively low across the sample. Female students were less likely to achieve the VPA or MSPA guidelines, but were more health conscious and in generally exhibited better academic performace than males. High health awareness and excellent/ very good self-rated health were the strongest predictors of achieving all forms of PA. Parents' education level was positively related to likelihood of achieving the VPA, MVPA and MSPA guidelines. Achieving the MPA guidelines (but not VPA or MSPA) was positively associated with subjective perceptions of better academic performance.

Conclusions: Achievement of PA guidelines was generally low for this sample of Finnish students, and was associated with positive health status and high health awareness. Universities need a holistic approach to improve awareness of health and promote PA in students' lifestyles.

Key words: physical activity guidelines, university students, Finland, gender, college health

Address for correspondence: W. El Ansari, Department of Surgery, Hamad General Hospital, PO Box 3050, Doha, Qatar. E-mail: welansari9@ gmail.com

https://doi.org/10.21101/cejph.a4387

\section{INTRODUCTION}

Physical activity (PA) levels of university students are a concern to educators and health authorities particularly that sedentary lifestyles are linked to $\approx 15 \%$ of the 1.6 million newly diagnosed chronic diseases each year (1). Most college students' PA patterns are not at ideal levels and worsen over time (2). For instance, in the USA, the prevalence of meeting public health moderate to vigorous PA (MVPA) recommendations among college students was $41.9 \%$ (3), and similar research confirms a generally low PA level across these young adult populations (4). In Egypt, only 16\% of the sample of university students achieved vigorous PA(VPA) guidelines, and about one third were physically inactive (5); and a more recent study reported that only one third of students achieved VPA guidelines (6). In Libya, a mere $11.2 \%$ of students achieved the VPA guidelines (7). One in three university students are sedentary and become less physically active through their college years (8-10); and whilst university students are generally the more educated segment of the population, college students gain weight at a rate $\approx 6$ times higher than that of the general population (11).

The relationships between PA and academic achievement are inconclusive. Studies in Finland (children) and elsewhere (adolescents) reported a positive association between PA and academic achievement $(12,13)$. In contrast, in Kuwait, there was no direct 
association between PA and academic achievement (14); and in the UK, there was no direct association between PA and students' academic achievement whether the indicator employed was subjective (self reported) or objective (actual module grade) (15).

Such inconsistent findings might be due to the many variables that influence the PA-academic achievement relationship. Living situations (e.g., dorm, off campus) may influence PA behaviours; and years of college study, gender, and environmental factors may be associated with college students' PA behaviours and weight changes $(2,16)$. In addition, studies of university students in Egypt and Mexico have reported some associations between some measures of socioeconomic status (e.g. father's highest education level) and students' attainment of PA guidelines $(6,17)$. Likewise, for self-rated health, among adults in Saudi Arabia, limited VPA was associated with poor/fair self-rated health (18); and conversely, among adolescents (12-17 years) in Canada, excellent/very good SRH was more frequently reported by active adolescents (19).

The literature reveals gaps. Whilst there exists Finnish PA studies, they seem to have focused on adolescents and young children (primary and lower secondary schools) rather than university students $(12,20,21)$. Other research in Finland that examined some PA aspects among young adults was either population based e.g. Finnish young adults (aged 18-29 years) (22); investigated certain groups e.g. military recruits (19-20 year olds) (23); or was population based and not wholly focused on PA and sedentary behaviours, e.g. as part of a large cardiovascular risk study or the young Finns study $(24,25)$. Still other research in Finland (26) tracked PA from early childhood through youth into adulthood, but did not go beyond the age of 18 years thus falling short of the age of most university populations. Very little research on aspects of university students' PA has been undertaken in Finland and the very few studies that undertook such a task frequently used small samples (27). This is despite that PA and physical inactivity are well-known protective and risk factors respectively for many chronic conditions; and, in school settings, movement can promote children's cognitive development (28), triggering the need to evaluate the fitness-academic performance connections (29). Since 2000, a national university student health survey in Finland was carried out only four times (30); and there is a dearth of government or country reports dedicated to the topic. Hence, the current study bridges these knowledge gaps to examine the factors, correlates and associations of PA and its gender differences; and associations between PA and academic achievement among Finnish undergraduates. These features attach high importance to the contributions of the current research.

The present survey of a representative sample of undergraduates at the University of Turku, Finland (7 faculties) assessed and compared, by gender, students' attainment of guidelines of four PA forms: moderate PA (MPA), vigorous PA (VPA), moderate to vigorous PA (MVPA), and muscle strengthening PA (MSPA). The study also explored the associations between two academic achievement variables (importance of achieving good grades; level of academic performance compared with one's peers) and attaining the guidelines of each of the four PA forms whilst simultaneously taking into account five socio-demographic variables (gender, age, year of study, highest education of either parent, living arrangements during university terms) and self-rated health. Hence we sought to describe and compare the levels of four PA forms, socio-demographic variables, and academic achievement by gen- der; explore the variables associated with achieving the guidelines of each of four PA forms (whole sample); and, assess whether the frequency of PA is associated with academic achievement.

\section{MATERIALS AND METHODS}

The study was a general student health and wellbeing survey similar to studies of student health implemented in several countries (31-37). It included self-reported socio-demographic data (e.g., gender, age, weight, height), information on various forms of PA, as well as university study (academic achievement) related questions.

\section{Sample, Ethics, and Data Collection}

The Research and Ethics Committee at the University approved the study, and survey data were collected using a secure online self-administered English questionnaire (2013-2014) at the University of Turku in Turku, Finland. An initial email (invitation to participate) was sent to all first, second and third year undergraduates at all faculties at the University outlining the study's aims and objectives and motivating students to complete the online survey. Participation was voluntary and anonymous (no incentives provided), and data were confidential and protected. Students were informed that by completing the online survey, they agree to participate in the study. As a follow up, two weeks after the initial email inviting the students, a reminder invitation email was sent again to all first, second and third year undergraduates. Furthermore, three posters about the study were positioned in the students' cafeteria at the University; and a reminder was posted on the University intra-web. A pilot survey was undertaken first (May 2013, random sample, 200 students) stratified by faculties. Very few participants reported any comprehensibility challenges related to the English questionnaire, and the number of missing values related to items that reasonably could be expected to be answered by all respondents was trivial. The main survey was then launched with the unmodified questionnaire (September 2013). The pilot sample was excluded from the final eligible sample that included 4,387 undergraduates at the University of Turku.

As students completed the online survey by clicking the 'submit' button, their electronic responses were automatically saved and directed to the Student Management Office at the University. The Student Management Office gathered the completed online responses, and the data were electronically entered into an excel sheet ensuring high quality assurance. After this phase was completed, the data was sent to the research team. We then electronically imported the data (no identifiers) into SPSS for the analysis. The total number of responses received was 1,177. Questionnaires were excluded where participants had not indicated their gender $(n=8)$, or where they had difficulty completing it in English (either answering that they had found it 'very difficult' to complete $(n=3)$, or not answering this question $(n=10)$. Therefore, 1,161 (345 males, 816 females) were included in the current analysis, and any other omissions were treated as missing values. Students' mean age was 23 (SD 5) years. Participating students were enrolled at all seven Faculties of the University of Turku (Humanities, Mathematics and Natural Sciences, Medicine, Law, Social Sciences, Education and Economics). Based on the number of returned questionnaires, the response rates were about $27 \%$. 


\section{Health and Well-being Questionnaire}

The questionnaire gathered general health/well-being data: socio-demographic variables (gender, age, year of study, religion), self-reported health (general health, health awareness, quality of life, height, weight), lifestyle behaviours (PA), and university related questions (academic performance, educational achievement). The questionnaire has been used and field-tested across different student populations $(6,7,15,31-37)$.

\section{Sociodemographic Variables}

Age, gender and year of study at university was self-reported by the students.

Living arrangements (accommodation during university semesters/terms) (1 item): "Where do you live during university/ college term time?" (living on campus vs. not living on campus).

Socioeconomic status (SES) (2 items): "What is the highest education level of your father?". The same question was also asked about mother's education level (no formal education, primary school, secondary school, high school, bachelor's degree, master's degree and Ph.D. or equivalent). For the current analysis, we employed the highest education of either parent.

\section{PA Variables}

MPA (1 item): "On how many of the past 7 days did you participate in moderate exercise for at least 30 minutes?" Participants responded with 0-7 days. We employed a cut-off of $\geq 5$ days/week (38).

VPA (1 item): "On how many of the past 7 days did you participate in vigorous exercise for at least 20 minutes?" Students responded with $0-7$ days. We employed $\mathrm{a} \geq 3$ days/week cut-off, in line with the American Heart Association guidelines (38).

MVPA (1 item): was computed by combining together moderate $\mathrm{PA}$ and vigorous PA. All students who achieved either moderate or vigorous $\mathrm{PA}$ at the recommended level were designated as achieving MVPA (AHA guidelines for vigorous PA) (38).

MSPA (1 item): "On how many of the past 7 days did you do exercises to strengthen or tone your muscles, such as push-ups, sit-ups, or weight lifting?" Participants answered 0-7 days. We used the cut-off of $\geq 2$ days/week (38).

Academic Performance/Educational Achievement Variables

One's academic performance in comparison with one's peers (1 item): "How do you rate your performance in comparison with your fellow students?" (5 response categories, $1=$ much worse, $5=$ much better) (15). For easy interpretation, the scale was reversed for the analysis.

Importance of achieving good grades at university (1 item): "How important is it for you to have good grades at university?" $(1=$ not at all important, $4=$ very important $)$. For easier interpretation, the scale was reversed for the analysis.

\section{Health Variables}

Self-rated general health (1 item): "How would you rate your health in general?", 5 -point response scale $(1=$ excellent, $2=$ very good, $3=$ good, $4=$ fair, $5=$ poor), similar wording was used by the American College Health Association $(39,40)$.

Heath awareness (Keep an eye on health, 1 item): "To what extent do you keep an eye on your health?", with four point response scale $(1=$ not at all, $4=$ very much).
Quality of life (1 item): "If you consider the quality of your life: How did things go for you in the last four weeks?" (5 categories, $1=$ very badly, 5 = very well) (41).

$B M I$ (reported): based on self reported weight and height, BMI was calculated using Metric BMI Formula: BMI $\left(\mathrm{kg} / \mathrm{m}^{2}\right)=$ weight in kilograms/squared height $\left(\mathrm{m}^{2}\right)$, and employed to group participants as: underweight $\left(\mathrm{BMI}<18.5 \mathrm{~kg} / \mathrm{m}^{2}\right)$, normal $(18.5 \leq$ BMI $\left.<24.9 \mathrm{~kg} / \mathrm{m}^{2}\right)$, overweight $\left(25.0 \leq \mathrm{BMI}<29.9 \mathrm{~kg} / \mathrm{m}^{2}\right)$, and obese $\left(\mathrm{BMI} \geq 30.0 \mathrm{~kg} / \mathrm{m}^{2}\right)(42)$.

\section{Other Variables}

Ease of completion of the questionnaire in English language (1 item): The online questionnaire was in English language and was not translated into Finnish as the great majority of students were proficient in English. Hence in the questionnaire, we included a question to inquire about the ease of completion of the questionnaire in English language: "Responding to a questionnaire in English was for me" (easy, rather easy, not as easy as if the questionnaire had been in my mother tongue, somewhat difficult, very difficult).

\section{Statistical Analysis}

Analyses were conducted employing the statistical package SPSS $14.0(\mathrm{p}<0.05)$. For the demographic and PA variables, frequencies were calculated separately for males and females. Gender comparisons were undertaken using chi-square $\left(\chi^{2}\right)$ statistics for categorical variables. Binary logistic regression analyses examined the factors associated with achieving recommended levels of four PA forms (MPA, VPA, MVPA, MSPA) as dependent variables, adjusting for gender and all other variables in the model. For the association between the frequency of the four forms of PA (per week) and level of academic achievement compared to peers (from much worse to much better), we performed linear regression analyses, adjusting for age, sex, parent's education, BMI, and self-rated general health. Pearson correlation coefficients for all these variables entered into the model were $<0.2$, suggesting that multicollinearity was not a substantial problem.

\section{RESULTS}

\section{Sociodemographic, Academic, Health, and PA Features by Gender}

The majority of participants were in the first 3 years of undergraduate study at university and there were small but significant gender differences across the years of study (Table 1). Most students were $\leq 25$ years old, with much fewer respondents in the $26-30$ and $\geq 30$ years age bands. About $80 \%$ of the sample did not live on university campus, with significantly more females living off campus. There were no differences in the highest education attainment of either parent. Although most participants regarded it very or somewhat important to achieve good grades in their university study, significantly more females than males regarded such achievement of good grades important.

More than $80 \%$ of the sample rated their own academic performance as better or the same when compared to their peers, with small but significant gender differences. About $75 \%$ of students 
had normal BMI (healthy weight), and females were significantly more likely to report normal BMI. The majority of students rated their health as excellent/very good/good; reported being health aware very much/to some extent; and rated their quality of life as very well/quite well, although there were significant gender differences across all these variables.

Achieving Guidelines of Four PA Forms by Gender

About the same proportions of students achieved the recommended MPA guidelines (males $16 \%$ vs. females 17\%), the
VPA guidelines (males 32\% vs. females 15\%), and the MVPA guidelines (37\% males vs. $35 \%$ females) (Table 1 and Fig. 1). Significantly more males (54\%) than females (36\%) achieved the MSPA guidelines.

\section{Variables Associated with Achieving Guidelines of Four Forms of PA}

Table 2 depicts the variables associated with achieving the guidelines of four PA forms. Females were significantly less likely to achieve the MSPA guideline; middle-aged students (21-25

Table 1. Sample characteristics and achievement of four PA guidelines

\begin{tabular}{|c|c|c|c|c|}
\hline \multirow[b]{2}{*}{ Variables } & Sample & Male & Female & \multirow[b]{2}{*}{$\mathrm{p}$} \\
\hline & $\begin{array}{c}n=1,161 \\
(\%)\end{array}$ & $\begin{array}{c}n=345 \\
(\%)\end{array}$ & $\begin{array}{c}n=816 \\
(\%)\end{array}$ & \\
\hline \multicolumn{5}{|c|}{ Socio-demographic } \\
\hline \multicolumn{5}{|l|}{ Year of study } \\
\hline 1st year & $545(47)$ & $177(51)$ & $368(45)$ & \multirow{4}{*}{0.019} \\
\hline 2nd year & $341(29)$ & $106(31)$ & $235(29)$ & \\
\hline 3rd year & $248(21)$ & $54(16)$ & $194(24)$ & \\
\hline$\geq 4$ th year & $23(2)$ & $6(2)$ & $17(2)$ & \\
\hline \multicolumn{5}{|l|}{ Age (years) } \\
\hline$\leq 20$ & $354(30)$ & $89(26)$ & $265(32)$ & \multirow{4}{*}{0.080} \\
\hline $21-25$ & $621(53)$ & $202(59)$ & $419(51)$ & \\
\hline $26-30$ & $111(10)$ & $35(10)$ & $76(9)$ & \\
\hline$\geq 30$ & $75(6)$ & $19(6)$ & $56(7)$ & \\
\hline \multicolumn{5}{|c|}{ Living arrangements (university campus) } \\
\hline Yes & $212(18)$ & $79(23)$ & $133(16)$ & \multirow[t]{2}{*}{0.006} \\
\hline No & $928(80)$ & $257(74)$ & $671(82)$ & \\
\hline \multicolumn{5}{|c|}{ Highest education of either parent } \\
\hline No formal education & $25(2)$ & $12(3)$ & $13(2)$ & \multirow{6}{*}{0.314} \\
\hline GCSE level & $33(3)$ & $7(2)$ & $26(3)$ & \\
\hline Alevel & $349(30)$ & $98(28)$ & $251(31)$ & \\
\hline Bachelor's & $206(18)$ & $65(19)$ & $141(17)$ & \\
\hline Master's & $417(36)$ & $124(36)$ & $293(36)$ & \\
\hline Doctorate & $131(11)$ & $39(11)$ & $92(11)$ & \\
\hline \multicolumn{5}{|c|}{ Academic } \\
\hline \multicolumn{5}{|c|}{ How important are good grades to you? } \\
\hline Very important & $210(18)$ & $43(13)$ & $167(20)$ & \multirow{4}{*}{$<0.001$} \\
\hline Somewhat important & $749(65)$ & $226(66)$ & $523(64)$ & \\
\hline Not very important & $181(16)$ & $63(18)$ & $118(14)$ & \\
\hline Not at all important & $15(1)$ & $10(3)$ & $5(1)$ & \\
\hline \multicolumn{5}{|c|}{ Rating of own academic performance compared to peers } \\
\hline Much better & $23(2)$ & $7(2)$ & $16(2)$ & \multirow{5}{*}{0.007} \\
\hline Better & $272(23)$ & $71(21)$ & $201(25)$ & \\
\hline The same & $686(59)$ & $204(59)$ & $482(59)$ & \\
\hline Worse & $157(14)$ & $50(14)$ & $107(13)$ & \\
\hline Much worse & $20(2)$ & $13(4)$ & $7(1)$ & \\
\hline
\end{tabular}

Continued on next page 
Continued from previous page

\begin{tabular}{|c|c|c|c|c|}
\hline \multirow[b]{2}{*}{ Variables } & Sample & Male & Female & \multirow[b]{2}{*}{$\mathrm{p}$} \\
\hline & $\begin{array}{c}n=1,161 \\
(\%)\end{array}$ & $\begin{array}{c}n=345 \\
(\%)\end{array}$ & $\begin{array}{c}n=816 \\
(\%)\end{array}$ & \\
\hline \multicolumn{5}{|c|}{ Health } \\
\hline \multicolumn{5}{|l|}{ BMl } \\
\hline Underweight & $75(7)$ & $10(3)$ & $65(8)$ & \multirow{3}{*}{$<0.001$} \\
\hline Normal & $850(74)$ & $227(67)$ & $623(78)$ & \\
\hline Overweight/obese & $214(19)$ & $103(30)$ & $111(14)$ & \\
\hline \multicolumn{5}{|l|}{ Self-rated Health } \\
\hline Excellent/very good & $622(54)$ & $199(58)$ & $423(52)$ & \multirow{3}{*}{0.001} \\
\hline Good & $447(38)$ & $108(31)$ & $339(41)$ & \\
\hline Fair/poor & $92(8)$ & $38(11)$ & $54(7)$ & \\
\hline \multicolumn{5}{|l|}{ Health awareness } \\
\hline Not much/not at all & $160(14)$ & $71(21)$ & $89(11)$ & \multirow{2}{*}{$<0.001$} \\
\hline Some extent/very much & $996(86)$ & $272(79)$ & $724(89)$ & \\
\hline \multicolumn{5}{|l|}{ Quality of life } \\
\hline Badly/very badly & $62(5)$ & $24(7)$ & $38(5)$ & \multirow{3}{*}{0.254} \\
\hline Intermediate & $259(22)$ & $73(21)$ & $186(23)$ & \\
\hline Quite/very well & $838(72)$ & $246(72)$ & $592(72)$ & \\
\hline \multicolumn{5}{|c|}{ Physical activity achievement } \\
\hline MPA guidelines & $196(17)$ & $54(16)$ & $142(17)$ & 0.467 \\
\hline VPA guidelines & $334(29)$ & $110(32)$ & $124(15)$ & 0.124 \\
\hline MVPA guidelines & $416(36)$ & $127(37)$ & $289(35)$ & 0.651 \\
\hline MSPA guidelines* & $479(41)$ & $186(54)$ & $293(36)$ & $<0.001$ \\
\hline
\end{tabular}

${ }^{*} \geq$ twice/week; bolded cell indicates statistical significance

years) were significantly more likely to achieve the VPA and MSPA guidelines; and higher SES students (highest education of either parent $\geq$ bachelor's degree) were significantly more likely to achieve the VPA, MVPA and MSPA guidelines. As regards the academic variables, students with self-reported better academic performance compared to peers were significantly more likely to achieve the MPA guideline. For the health variables, normal BMI participants were significantly less likely to achieve the MPA,

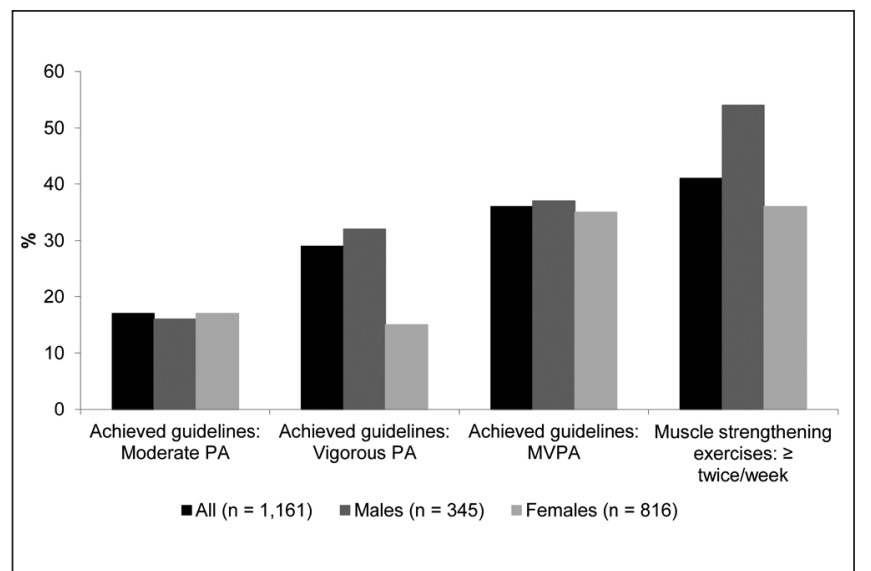

Fig. 1. Achievement of four PA guidelines for whole sample and by gender.
VPA and MVPA guidelines, and overweight/obese students were significantly more likely to achieve the MSPA guidelines. Finally, higher health awareness and better self-rated health were both significantly associated with achieving all four PA guidelines. All the other variables had no significant associations with achieving the guidelines of any of the four PA forms.

\section{Association Between Frequency of PA and Academic Achievement}

Increasing frequencies of both MPA and MVPA were positively associated with increasing perceived academic performance compared to one's peers (Table 3 ). The magnitudes of both associations were nearly similar (0.08), and the standardised Betas $(\beta)$ for both associations were relatively small $(0.020-0.026)$, denoting a modest correlation between academic performance compared to one's peers and PA frequency. None of the four PA forms were significantly associated with the subjective importance of achieving good grades.

\section{DISCUSSION}

About $17 \%$ of our students achieved the MPA guidelines, $29 \%$ achieved the VPA guidelines, 36\% achieved the MVPA guidelines, and $41 \%$ achieved the MSPA guidelines. Our observed 
Table 2. Variables associated with achieving recommended guidelines of four PA forms

\begin{tabular}{|c|c|c|c|c|}
\hline & \multicolumn{4}{|c|}{ Achieved recommended guidelines of } \\
\hline & Moderate PA & Vigorous PA & Moderate to vigorous PA & Muscle strengthening PA \\
\hline Variable & \multicolumn{4}{|c|}{$\operatorname{Exp}(\beta)(95 \% \mathrm{Cl})$} \\
\hline \multicolumn{5}{|l|}{ Year of study } \\
\hline 1st or 2 nd year & 1.00 & 1.00 & 1.00 & 1.00 \\
\hline$\geq 3$ rd year & $0.98(0.66-1.46)$ & $0.84(0.59-1.20)$ & $0.87(0.63-1.20)$ & $0.76(0.54-1.05)$ \\
\hline \multicolumn{5}{|l|}{ Gender } \\
\hline Male & 1.00 & 1.00 & 1.00 & 1.00 \\
\hline Female & $1.02(0.82-1.73)$ & $0.80(0.59-1.09)$ & $0.93(0.69-1.24)$ & $0.40(0.30-0.54)$ \\
\hline \multicolumn{5}{|l|}{ Age (years) } \\
\hline$\leq 20$ & 1.00 & 1.00 & 1.00 & 1.00 \\
\hline $21-25$ & $0.94(0.55-1.59)$ & $1.77(1.12-2.81)$ & $1.41(0.92-2.15)$ & $1.56(1.01-2.39)$ \\
\hline$\geq 26$ & $1.03(0.65-1.63)$ & $1.29(0.86-1.96)$ & $1.14(0.79-1.67)$ & $1.41(0.97-2.08)$ \\
\hline \multicolumn{5}{|c|}{ Living arrangements (accommodation) } \\
\hline University campus & 1.00 & 1.00 & 1.00 & 1.00 \\
\hline Not university campus & $1.13(0.73-1.74)$ & $1.36(0.94-1.96)$ & $1.29(0.92-1.81)$ & $0.98(0.70-1.37)$ \\
\hline \multicolumn{5}{|c|}{ Highest education of either parent } \\
\hline$\leq$ Alevel & 1.00 & 1.00 & 1.00 & 1.00 \\
\hline$\geq$ Bachelor's degree & $1.31(0.92-1.86)$ & $1.48(1.10-2.00)$ & $1.39(1.06-1.84)$ & $1.43(1.10-1.89)$ \\
\hline \multicolumn{5}{|l|}{ Importance of good grades } \\
\hline Not very/not at all important & 1.00 & 1.00 & 1.00 & 1.00 \\
\hline Somewhat/very important & $1.01(0.64-1.61)$ & $1.17(0.79-1.73)$ & $1.17(0.81-1.68)$ & $0.92(0.64-1.32)$ \\
\hline \multicolumn{5}{|c|}{ Academic performance compared to peers } \\
\hline The same/worse & 1.00 & 1.00 & 1.00 & 1.00 \\
\hline Better & $1.48(1.04-2.10)$ & $1.09(0.80-1.48)$ & $1.25(0.93-1.67)$ & $1.17(0.87-1.57)$ \\
\hline \multicolumn{5}{|l|}{ BMI } \\
\hline Underweight & 1.00 & 1.00 & 1.00 & 1.00 \\
\hline Normal & $0.62(0.28-1.35)$ & $0.37(0.18-0.76)$ & $0.48(0.26-0.90)$ & $1.04(0.56-1.95)$ \\
\hline Overweight/obese & $0.75(0.49-1.14)$ & $0.73(0.51-1.05)$ & $0.72(0.52-1.02)$ & $1.46(1.03-2.07)$ \\
\hline \multicolumn{5}{|l|}{ Health awareness } \\
\hline Not much/not at all & 1.00 & 1.00 & 1.00 & 1.00 \\
\hline Some extent/very much & $2.11(1.15-3.88)$ & $3.04(1.81-5.10)$ & $2.32(1.50-3.60)$ & $4.43(2.78-7.07)$ \\
\hline \multicolumn{5}{|l|}{ Quality of life rating } \\
\hline Badly/very badly & 1.00 & 1.00 & 1.00 & 1.00 \\
\hline Intermediate & $0.53(0.18-1.53)$ & $1.09(0.55-2.14)$ & $0.93(0.49-1.76)$ & $1.30(0.71-2.37)$ \\
\hline Quite/very well & $1.45(0.97-2.18)$ & $1.13(0.79-1.61)$ & $1.23(0.88-1.71)$ & $1.11(0.80-1.56)$ \\
\hline \multicolumn{5}{|l|}{ Self-rated health } \\
\hline Good/ fair/poor & 1.00 & 1.00 & 1.00 & 1.00 \\
\hline Excellent/very good & $1.88(1.31-2.69)$ & $2.02(1.50-2.72)$ & $1.98(1.50-2.62)$ & $2.18(1.65-2.88)$ \\
\hline
\end{tabular}

$\mathrm{Cl}$ - confidence interval; bolded cells indicate statistical significance

36\% MVPA guideline achievement (whole sample) is in line with undergraduates in the USA $(41.9 \%$ prevalence of meeting public health MVPA recommendations) (3). Likewise, our observed $17 \%$ MPA guideline achievement (whole sample) supports the 12.4\% MPA guideline achievement level reported across UK universities (36); and our 29\% VPA guideline achievement (whole sample) was close to the $33.1 \%$ VPA guideline achievement level of students enrolled at seven universities in England, Wales and Northern Ireland (36). However, our whole sample's MSPA guidelines achievement (41\%) was higher than the $23.9 \%$ reported for undergraduates in the UK (36), suggesting that muscle stretching and muscle strengthening workouts, muscle conditioning activities and muscle toning generally might be more popular among Finnish/Scandinavian students than in the UK. Nevertheless, 
Table 3. Association between academic performance and frequency of four PA forms

\begin{tabular}{|l|c|c|c|c|}
\hline & \multicolumn{4}{|c|}{ Frequency of all form of PA in days per week } \\
\hline & Moderate PA & Vigorous PA & Moderate to vigorous PA & Muscle strengthening PA \\
\hline Adjusted R $(\beta)$ & 0.026 & 0.022 & 0.026 & 0.020 \\
\hline $\begin{array}{l}\text { One's academic performance } \\
\text { compared to peers }\end{array}$ & $0.086(p=0.005)$ & $0.057(p=0.074)$ & $0.085(p=0.007)$ & $0.035(p=0.274)$ \\
\hline Adjusted R $(\beta)$ & 0.020 & 0.020 & 0.021 & 0.020 \\
\hline Important to achieve good grades & $-0.017(p=0.581)$ & $-0.009(p=0.776)$ & $-0.011(p=0.732)$ & $0.015(p=0.632)$ \\
\hline
\end{tabular}

Standardised beta coefficients based on linear regression analysis adjusted for sex, age, parent education, BMI and health awareness; bolded cells indicate statistical significance

our observed various PA guidelines achievement levels were all $<50 \%$, representing a concern for the health/wellbeing of these young adults. Hence, coordinated efforts and interventions need to target these Finnish undergraduates to promote active lifestyles and more PA.

Our observed association between increasing frequency of four forms of PA and perceived academic performance compared to one's peers was only significant for MPA and MVPA (not for the other two PA forms). Such selectivity in the relationship between academic performance and only some particular PA forms but not others agrees with other studies. Among students of 11 faculties in Egypt, increasing frequencies of MVPA, VPA, and MSPA (but not MPA) were positively associated with increasing academic achievement (6). Likewise, among Dutch adolescents, overall, there was no significant dose-response association between PA and academic achievement; however, in grade 7, total PA volume (Total PA) was negatively associated with academic achievement, while MVPA was negatively associated with both academic achievement and mathematics performance. In contrast, in grade 9, both total PA and MVPA were positively associated with mathematics performance (43). Our observation of a positive association between MPA frequency and academic achievement (expressed as academic performance compared to peers) also supported other research, where high levels of regular PA were associated with higher selfperceived overall academic performance $(44,45)$.

Our students with better academic performance compared to peers were more likely to achieve the MPA guideline, similar to findings among adolescents, where not having a high level of academic achievement was associated with higher noncompliance to PA recommendations (46). However, in Finland, self-reported PA was directly associated with academic achievement; but, objectively measured PA was not associated with academic achievement (12); and among first-year university students in Switzerland, better PA did not predict better learning goal achievement; and day-to-day PA was not related to daily learning goal achievement (47). As for the second indicator of academic achievement, we observed that none of the four PA forms was significantly associated with the subjective importance of achieving good grades. Such associations of PA with one indicator of academic performance but not with the other is in line with published research and comfirms the complexity of the relationships between the various PA forms and different indicators of subjective or objective academic performance. Future research should examine which/whether particular PA forms exhibit consistent relationships with particular indicators of subjective academic achievement if any.
In terms of the strength (magnitude) of the association between academic achievement and PA frequency, our observed standardised Beta (0.026) for the positive significant association between perceived academic performance compared to one's peers and PA frequency was modest, as similarly reported in Egypt (employing the same research instrument), where the standardised $\beta$ ranged between 0.05-0.07 (6). Others have proposed that the association between academic achievement and PA is subject to PA intensity (48); is complex, and might be affected by academic year, PA volume and intensity, and school grade (43). Such findings confirm the breadth of interlacing variables that contribute to the PA-academic achievement relationships.

As for gender, about the same proportions of our students achieved the MPA guidelines (16\% of males vs. $17 \%$ of females), VPA guidelines ( $32 \%$ of males vs. $15 \%$ of females), and MVPA guidelines ( $37 \%$ of males vs. $35 \%$ of females). However, significantly more males than females achieved the MSPA guidelines (54\% males vs. $36 \%$ of females). We are in partial agreement with undergraduates across 11 faculties in Egypt, where female students were significantly less likely to achieve not only the recommended MSPA guidelines, but also the VPA and MVPA guidelines (except for MPA) (6). Generally, less females achieve PA recommendations (17).

In terms of the variables associated with achieving the guidelines of each of four PA forms for the whole sample, females were significantly less likely to achieve the MSPA guideline (discussed above). Age-wise, our middle-aged students (21-25 years) were significantly more likely to achieve the VPA and MSPA guidelines, congruent with Egypt, where older students were significantly less likely to achieve the VPA, MVPA and MSPA guidelines (6). In support, the Spanish HBSC survey (adolescents) reported that being female and being older were associated with higher non-compliance to PA recommendations (49). In addition, our students' SES (highest education of either parent $\geq$ bachelor's degree) was significantly positively associated with achieving the VPA, MVPA and MSPA guidelines, in agreement with Egypt, where father's education was positively associated with VPA and MVPA guidelines attainment (6), and in support of Mexico, where medium-high socioeconomic level students reported more activity (17).

As for the health variables, our overweight/obese students were less likely to achieve the MPA, VPA and MVPA guidelines, similar to a statewide cross-sectional survey in Australia, where overweight persons were less likely to achieve 10,000 steps/day (50). Likewise, attitudes and health awareness could also have an impact on PA (51), and across our sample, higher health aware- 
ness and better self-rated health were both significantly associated with achieving all four PA guidelines, in line with Egypt, where students with very good/excellent self-rated health were more likely to achieve the VPA, MVPA and MSPA guidelines (6).

The study has limitations. We examined 7 faculties at one university, and selection bias cannot be ruled out. We did not operationalize other variables that could be associated with PA: biological (parental BMI), behavioural (TV/computer habits, sports club membership, time outdoors), physical environmental (neighbourhood features), psychological (self-esteem), and seasonal features. As a cross-sectional survey, no conclusions on direction of influence can be derived. Self-reporting of the estimated PA levels could be subject to social desirability and sociability bias; objectively measured PA was not undertaken. Whilst the questionnaire inquired about various forms of PA, we did not explicitly indicate in the questionnaire what MPA and VPA entail, as we explicitly indicated what MSPA entailed. Although MPA and VPA are clear entities, particularly for young healthy adults, we cannot exclude that some students might have not been absolutely clear about what each of these two types of PA entailed. Academic achievement was also self-reported. We included a question about the ease of completion of the questionnaire in English language, and questionnaires were excluded from the analysis where participants had difficulty completing it in English, either answering that they had found it very difficult to complete $(n=3)$, or not answering this question $(n=10)$; nevertheless, despite that the great majority of Finnish students are well versed in English language, we cannot conclude that the English questionnaire was easy for all participants to complete. Despite these limitations, the study has important strengths. The large sample size (and representativeness) across many faculties enabled the calculation of precise estimates for the different variables. We also measured four different PA forms (rather than solely relying on total PA, in line with the importance of analyzing domain and intensity-specific PA levels among students); and two different academic achievement variables. The study's findings confirm some of the relationships but, in contrast to other research, in the current survey, multiple variables that could be associated with university students' PA were considered simultaneously (adjusted model). This adjustment could have possibly resulted in fewer significant associations than with other techniques, e.g. univariate analysis. To the best of our knowledge, no previous study investigated in detail the levels, gender differences and correlates of PA of university students in Finland.

\section{CONCLUSION}

Achievement of PA guidelines was generally low for this sample of Finnish students, and was associated with positive health status and with high health awareness. Universities would benefit from multipronged strategies and approaches employing effective interventions aimed at improving students' general awareness of their health and promoting more physically active lifestyles among students.

\section{Acknowledgements}

The authors acknowledge the University, the Faculties and students who participated in this study, and thank the Student Management Office at the University of Turku for their assistance with the online survey and inputs in data collection.

\section{Conflict of Interests}

None declared

\section{REFERENCES}

1. Martin CK, Church TS, Thompson AM, Earnest CP, Blair SN. Exercise dose and quality of life: a randomized controlled trial. Arch Intern Med. 2009 Feb 9;169(3):269-78.

2. Small M, Bailey-Davis L, Morgan N, Maggs J. Changes in eating and physical activity behaviors across seven semesters of college: living on or off campus matters. Health Educ Behav. 2013 Aug;40(4):435-41.

3. Wald A, Muennig PA, O'Connell KA, Garber CE. Associations between healthy lifestyle behaviors and academic performance in U.S. undergraduates: a secondary analysis of the American College Health Association's National College Health Assessment II. Am J Health Promot. 2014 MayJun;28(5):298-305.

4. Muttappallymyalil J, Mathew E, Sreedharan J, Al Sharbatii S, Shaikh RB, Basha SA. Self reported physical activity among University Students in Ajman, UAE. Pak J Med Sci. 2010;26(4):782-6.

5. Abolfotouh MA, Bassiouni FA, Mounir GM, Fayyad RCh. Health-related lifestyles and risk behaviours among students living in Alexandria University Hostels. East Mediterr Health J. 2007 Mar-Apr;13(2):376-91.

6. El Ansari W, Stock C. Relationship between attainment of recommended physical activity guidelines and academic achievement: undergraduate students in Egypt. Glob J Health Sci. 2014 Jul 14;6(5):274-83.

7. El Ansari W, Khalil K, Crone D, Stock C. Physical activity and gender differences: correlates of compliance with recommended levels of five forms of physical activity among students at nine universities in Libya. Cent Eur J Public Health. 2014 Jun;22(2):98-105.

8. Huang TT, Harris KJ, Lee RE, Nazir N, Born W, Kaur H. Assessing overweight, obesity, diet, and physical activity in college students. J Am Coll Health. 2003 Sep-Oct;52(2):83-6.

9. Morrow ML, Heesch KC, Dinger MK, Hull HR, Kneehans AW, Fields DA. Freshman 15: fact or fiction? Obesity (Silver Spring). 2006 Aug;14(8):1438-43.

10. Racette SB, Deusinger SS, Strube MJ, Highstein GR, Deusinger RH. Changes in weight and health behaviors from freshman through senior year of college. J Nutr Educ Behav. 2008 Jan-Feb;40(1):39-42.

11. Mihalopoulos NL, Auinger P, Klein JD. The Freshman 15: is it real? J Am Coll Health. 2008 Mar-Apr;56(5):531-3.

12. Syväoja HJ, Kantomaa MT, Ahonen T, Hakonen H, Kankaanpää A, Tammelin TH. Physical activity, sedentary behavior, and academic performance in Finnish children. Med Sci Sports Exerc. 2013 Nov;45(11):2098104.

13. Shin YS, So WY. Association between Physical Inactivity and Academic Record in Korean Adolescents. Iran J Public Health. 2012;41(10):36-42.

14. Al-Kandari F, Vidal VL. Correlation of the health-promoting lifestyle, enrollment level, and academic performance of College of Nursing students in Kuwait. Nurs Health Sci. 2007 Jun;9(2):112-9.

15. El Ansari W, Stock C. Is the health and wellbeing of university students associated with their academic performance? Cross sectional findings from the United Kingdom. Int J Environ Res Public Health. 2010 Feb;7(2):509-27.

16. Kapinos KA, Yakusheva O. Environmental influences on young adult weight gain: evidence from a natural experiment. J Adolesc Health. 2011 Jan;48(1):52-8.

17. Ulla Díez SM, Pérez-Fortis A. Socio-demographic predictors of health behaviors in Mexican college students. Health Promot Int. 2010 Mar;25(1):85-93.

18. Moradi-Lakeh M, El Bcheraoui C, Tuffaha M, Daoud F, Al Saeedi M, Basulaiman M, et al. Self-Rated Health Among Saudi Adults: Findings from a National Survey, 2013. J Community Health. 2015 Oct;40(5):920-6.

19. Herman KM, Hopman WM, Sabiston CM. Physical activity, screen time and self-rated health and mental health in Canadian adolescents. Prev Med. 2015 Apr;73:112-6.

20. Haapala HL, Hirvensalo MH, Laine K, Laakso L, Hakonen H, Lintunen $\mathrm{T}$, et al. Adolescents' physical activity at recess and actions to promote a physically active school day in four Finnish schools. Health Educ Res. 2014 Oct;29(5):840-52. 
21. Jaakkola T, Kalaja S, Liukkonen J, Jutila A, Virtanen P, Watt A. Relations among physical activity patterns, lifestyle activities, and fundamenta movement skills for Finnish students in grade 7. Percept Mot Skills. 2009 Feb;108(1):97-111.

22. Kestilä L, Mäki-Opas T, Kunst AE, Borodulin K, Rahkonen O, Prättälä R. Childhood adversities and socioeconomic position as predictors of leisure-time physical inactivity in early adulthood. J Phys Act Health. 2015 Feb;12(2):193-9.

23. Mikkola I, Jokelainen JJ, Timonen MJ, Härkönen PK, Saastamoinen E, Laakso MA, et al. Physical activity and body composition changes during military service. Med Sci Sports Exerc. 2009 Sep;41(9):1735-42.

24. Yang X, Hirvensalo M, Hintsanen M, Hintsa T, Pulkki-Råback L, Jokela $\mathrm{M}$, et al. Longitudinal associations between changes in physical activity and depressive symptoms in adulthood: the young Finns study. Int $\mathrm{J}$ Behav Med. 2014 Dec;21(6):908-17.

25. Heinonen I, Helajärvi H, Pahkala K, Heinonen OJ, Hirvensalo M, Pälve $\mathrm{K}$, et al. Sedentary behaviours and obesity in adults: the Cardiovascular Risk in Young Finns Study. BMJ Open. 2013 Jun 20;3(6). pii: e002901. doi: 10.1136/bmjopen-2013-002901.

26. Telama R, Yang X, Leskinen E, Kankaanpää A, Hirvensalo M, Tammelin $\mathrm{T}$, et al. Tracking of physical activity from early childhood through youth into adulthood. Med Sci Sports Exerc. 2014;46(5):955-62.

27. Kuuppelomäki M, Utriainen P. A 3 year follow-up study of health care students' sense of coherence and related smoking, drinking and physical exercise factors. Int J Nurs Stud. 2003 May;40(4):383-8.

28. Reed JA, Einstein G, Hahn E, Hooker SP, Gross VP, Kravitz J. Examining the impact of integrating physical activity on fluid intelligence and academic performance in an elementary school setting: a preliminary investigation. J Phys Act Health. 2010 May;7(3):343-51.

29. Van Dusen DP, Kelder SH, Kohl HW 3rd, Ranjit N, Perry CL. Association of physical fitness and academic performance among schoolchildren. J Sch Health. 2011 Dec;81(12):733-40.

30. Kunttu K, Pesonen T. Student Health Survey 2012: a national survey among Finnish university students [Internet]. Helsinki: Finnish Student Health Service; 2013 [cited 2016 Dec 16]. Available from: http://www. yths.fi/filebank/1864-KOTT 2012 verkkoon.pdf. (In Finnish.)

31. El Ansari W, Adetunji H, Oskrochi R. Food and mental health: relationship between food and perceived stress and depressive symptoms among university students in the United Kingdom. Cent Eur J Public Health. 2014 Jun;22(2):90-7.

32. El Ansari W, Dibba E, Stock C. Body image concerns: levels, correlates and gender differences among students in the United Kingdom. Cent Eur J Public Health. 2014 Jun;22(2):106-17.

33. El Ansari W, Oskrochi R, Haghgoo G. Are students' symptoms and health complaints associated with perceived stress at university? Perspectives from the United Kingdom and Egypt. Int J Environ Res Public Health. 2014 Sep 26;11(10):9981-10002.

34. El Ansari W, Stock C, Mikolajczyk RT. Relationships between food consumption and living arrangements among university students in four European countries - a cross-sectional study. Nutr J. 2012 Apr 24;11:28. doi: 10.1186/1475-2891-11-28.

35. El Ansari W, Stock C, Mills C. Is alcohol consumption associated with poor academic achievement in university students? Int J Prev Med. 2013 Oct;4(10):1175-88.

36. El Ansari W, Stock C, Phillips C, Mabhala A, Stoate M, Adetunji H, et al. Does the association between depressive symptomatology and physical activity depend on body image perception? A survey of students from seven universities in the UK. Int J Environ Res Public Health. 2011 Feb;8(2):281-99.
37. El Ansari W. Health and well - being of students at higher education institutions - time for urgent action? Cent Eur J Public Health. 2014 Jun;22(2):67.

38. Haskell WL, Lee IM, Pate RR, Powell KE, Blair SN, Franklin BA, et al.; American Heart Association. Physical activity and public health: updated recommendation for adults from the American College of Sports Medicine and the American Heart Association. Circulation. 2007 Aug 28;116(9):1081-93.

39. Potthoff P, Schroeder E, Reis U, Klamert A. Process and results of field work concerning the Federal Health Survey. Gesundheitswesen. 1999 Dec;61 Spec No:S62-7. (In German.)

40. American College Health Association. American College Health Association - National College Health Assessment: reference group data report fall 2005 [Internet]. Baltimore: American College Health Association; 2006 [cited 2013 May 14]. Available from: http://www.acha-ncha.org/ docs/ACHA-NCHA Reference Group Report Fall2005.pdf.

41. Bruusgaard D, Nessiøy I, Rutle O, Furuseth K, Natvig B. Measuring functional status in a population survey. The Dartmouth COOP functional health assessment charts/WONCA used in an epidemiological study. Fam Pract. 1993 Jun;10(2):212-8.

42. World Health Organization. Obesity: preventing and managing the global epidemic. Geneva: WHO; 2000.

43. Van Dijk ML, De Groot RH, Savelberg HH, Van Acker F, Kirschner PA. The association between objectively measured physical activity and academic achievement in Dutch adolescents: findings from the GOALS study. J Sport Exerc Psychol. 2014 Oct;36(5):460-73.

44. Fedewa AL, Ahn S. The effects of physical activity and physical fitness on children's achievement and cognitive outcomes: a meta-analysis. Res Q Exerc Sport. 2011 Sep;82(3):521-35.

45. Kantomaa MT, Tammelin TH, Demakakos P, Ebeling HE, Taanila AM Physical activity, emotional and behavioural problems, maternal education and self-reported educational performance of adolescents. Health Educ Res. 2010 Apr;25(2):368-79.

46. Galán I, Boix R, Medrano MJ, Ramos P, Rivera F, Pastor-Barriuso R, et al. Physical activity and self-reported health status among adolescents: a cross-sectional population-based study. BMJ Open. 2013 May 14;3(5) pii: e002644. doi: 10.1136/bmjopen-2013-002644.

47. Flueckiger L, Lieb R, Meyer AH, Mata J. How health behaviors relate to academic performance via affect: an intensive longitudinal study. PLoS One. 2014 Oct 29;9(10):e111080. doi: 10.1371/journal.pone.0111080.

48. Ayan C, Cancela Carral J, Montero C. Academic performance of young competitive swimmers is associated with physical activity intensity and its predominant metabolic pathway: a pilot study. J Phys Act Health. 2014 Sep;11(7):1415-9.

49. Galán I, Boix R, Medrano MJ, Ramos P, Rivera F, Moreno C. Individual factors and school-based policies related to adherence to physical activity recommendations in Spanish adolescents. Prev Sci. 2014 Aug;15(4):58899.

50. McCormack G, Giles-Corti B, Milligan R. Demographic and individual correlates of achieving 10,000 steps/day: use of pedometers in a population-based study. Health Promot J Austr. 2006 Apr;17(1):43-7.

51. Lowry R, Lee SM, Fulton JE, Demissie Z, Kann L. Obesity and other correlates of physical activity and sedentary behaviors among US high school students. J Obes. 2013;2013:276318. doi: 10.1155/2013/276318. 